\title{
Effect of diluents on blood clot lysis
}

\author{
M. J. GALLIMORE \\ From the Department of Biochemical Pharmacology, Therapeutics Research Division, \\ Pfizer Limited, Sandwich, Kent
}

SYNOPSIS One of the current methods used for measuring natural fibrinolytic activity in blood involves dilution of the blood with phosphate buffer. An adaptation of this method using a solution of sodium acetate as diluent is described. Evidence is given to show that dilute blood clots lyse not i $^{\circ}$ only because of the dissociation of an antiplasmin-plasmin complex, but also by virtue of a reduction of the intrinsic chloride ion concentration.

In 1937 Macfarlane observed that whereas clots prepared from the plasma of post-operative patients remained apparently unchanged for several days, clots prepared from the same plasma after dilution with buffered saline dissolved on standing overnight. This observation formed the basis of a number of methods for studying fibrinolytic activity in blood; dilutions of plasma were made in buffered saline, or in buffer alone, and the fibrinolytic activity was related to either the amount of clot which lysed in a given time, or the time taken for complete lysis of the clot (Mole, 1948; Bidwell, 1953; Fearnley and Tweed, 1953; Truelove, 1953; Fearnley and Lackner, 1955).

Subsequently Fearnley, Balmforth, and Fearnley (1957) developed a method for measuring fibrinolytic activity in diluted blood. They found that blood from rested female subjects lysed in less than 10 hours when diluted to a concentration of $10 \%$ with phosphate buffer and clotted with thrombin. Later, Chakrabarti and Fearnley (1962) prepared a range of blood dilutions and noted the highest blood concentration which had lysed after 12 hours' incubation; this they termed the 'fibrinolytic potential'.

Studies of the inhibition of fibrinolysis by serum in systems containing the plasminogen activator urokinase and plasminogen-rich fibrin, indicated that various ions, particularly chloride and sulphate, potentiated the inhibitory activity (Gallimore, Nulkar, and Shaw, 1965). In more recent experiments it was found that not only was the inhibition of plasminogen activation by urokinase in the presence of human serum highly dependent on the concentration of chloride in the medium, but that serum levels which were capable of inhibiting the lysis of plasminogen-deficient fibrin by plasmin in

Received for publication 8 November 1966. the absence of chloride, produced no inhibition? where fibrin-bound plasminogen was activated to 3 plasmin by urokinase in situ.

The dilute blood clot methods of Fearnley et al. $\vec{\theta}$ (1957) and of Chakrabarti and Fearnley (1962)。 involve dilution of blood with phosphate buffer. Recently it has been found that phosphate ionso have only a slight potentiating effect on the inhibition by plasma or serum in a system where plasminogen is activated to plasmin by urokinase.

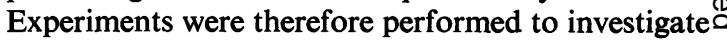
the possibility that clots made from blood diluted $\overrightarrow{\vec{O}}$ with phosphate buffer lyse by virtue of the dilution 3 of the chloride ions in blood.

\section{MATERIALS AND METHODS}

PLASMINOGEN-RICH FIBRINOGEN Bovine fibrinogen'음 (Plasma Fraction I) 12 g., containing 3-4 g. fibrinogen, was dissolved in $800 \mathrm{ml}$. of $0.05 \mathrm{M}$ sodium phosphate buffer ( $p H$ 6.5) and filtered. The solution was warmed to 3 $20^{\circ} \mathrm{C}$. and $220 \mathrm{ml}$. of saturated $\left(\mathrm{NH}_{4}\right)_{2} \mathrm{SO}_{4}$ was addedo slowly with stirring. After standing for two hours the precipitate was collected by centrifugation and re- $\frac{D}{0}$ dissolved in $0.1 \mathrm{M}$ trisodium citrate $(150 \mathrm{ml}$.). The resulting solution was dialysed for 24 hours against $N$ several changes of $0.05 \mathrm{M}$ trisodium citrate, filtered and freeze dried. The resulting fibrinogen contained over $90 \%$ clottable protein and gave lysis times of $14 \mathrm{~min}$. or less with 10 units of urokinase under the conditions of the standard clot assay described below.

THROMBIN Thrombin ${ }^{2}$ was dissolved in a $1: 1$ saline- $\overline{\mathscr{D}}$ glycerol mixture to give a stock solution containing? 1,000 N.I.H. units/mi.; this was diluted immediately before use.

UROKINASE 'Standard reference urokinase'3 contained $\stackrel{\odot}{\oplus}$ approximately 800 Ploug units/mg. Solutions were made@

${ }^{1}$ Armour Laboratories, Eastbourne, England.

2, 'Leo Laboratories, Hayes, Middlesex, England. 
in phosphate buffer 1 shortly before use and kept in ice water.

COLLECTION OF BLOOD Blood was obtained by venepuncture from male laboratory staff either after being seated for 15 minutes or after exercise (running up and down a flight of stairs for five minutes). For dilute clot lysis studies, the blood was immediately cooled by transferring it to a test tube standing in crushed ice. The blood was then diluted and clotted within two minutes. Plasma was obtained by mixing $9 \mathrm{ml}$. blood with $1 \mathrm{ml}$. $0 \cdot 1 \mathrm{M}$ ammonium oxalate and centrifuging, at $2^{\circ} \mathrm{C}$. for $5 \mathrm{~min}$. (6,000 r.p.m.), and used immediately.

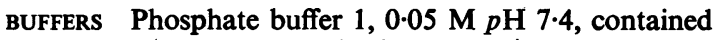
1.29 g. $\mathrm{NaH}_{2} \mathrm{PO}_{4} 2 \mathrm{H}_{2} \mathrm{O}$ and $5.93 \mathrm{~g}$. $\mathrm{Na}_{2} \mathrm{HPO}_{4}$ per litre.

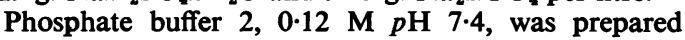
according to the method of Fearnley et al. (1957).

SALT SOLUTIONS Solutions of phosphoric, hydrochloric and acetic acids, all $0.75 \mathrm{M}$, were adjusted to $p \mathrm{H} 7.4$ with sodium hydroxide solution and diluted to $0.5 \mathrm{M}$ with distilled water.

DILUTE BLOOD CLOT LYSIS The method used was essentially that of Chakrabarti and Fearnley (1962). For each of the three diluents investigated (phosphate buffer $2,0 \cdot 12 \mathrm{M}$ sodium acetate and $0 \cdot 12 \mathrm{M}$ sodium chloride) a series of seven blood dilutions was prepared; these were arranged to give final blood concentrations of $5,7 \cdot 5$, $10 \cdot 0,12 \cdot 5,15,17 \cdot 5$, and $20 \%$. The total volume of each test system was $2.0 \mathrm{ml}$, and included $0.1 \mathrm{ml}$. of thrombin solution ( 50 units $/ \mathrm{ml}$.) diluted in the appropriate salt solution. After mixing the contents, the tubes were transferred to a $37^{\circ} \mathrm{C}$. water bath. Approximately 10 minutes after the addition of the thrombin the tubes were rotated briskly between the palms of the hands to release the clots from the sides of the tubes. The lysis times were recorded when the clots had disintegrated completely.

STANDARD CLOT LYSIS Into a series of test tubes $(10 \times$ $1 \mathrm{~cm}$.) in an ice-water bath were pipetted the following: $0.05 \mathrm{ml}$. human plasma, volumes of the salt solutions being studied calculated to give final concentrations of between 0.03 and $0.15 \mathrm{M}, 0.1 \mathrm{ml}$. of a solution of urokinase (100 units $/ \mathrm{ml}$.), and $0.2 \mathrm{ml} .1 \% \mathrm{~W} / \mathrm{V}$ fibrinogen. Buffer was then added to give a volume of $0.9 \mathrm{ml}$. and the solutions were clotted with $0.1 \mathrm{ml}$. thrombin (50 units/ $\mathrm{ml}$.). All the components were dissolved in, or diluted with, phosphate buffer 1 and after the addition of thrombin the contents were mixed and the tubes transferred to a $37^{\circ} \mathrm{C}$. water bath. A stop-watch was started when the thrombin was added, and the lysis times were recorded when air bubbles which formed in the clots rose to the surface.

\section{RESULTS}

The clot lysis times for blood from a rested subject diluted with either sodium acetate, phosphate buffer 2 , or sodium chloride, all at $0.12 \mathrm{M}$ and $p \mathrm{H} 7 \cdot 4$, were measured and the results are shown in Figure 1. The remarkable feature of these results is the fact that while the $10 \%$ blood concentration in sodium chloride had failed to lyse during the time of observation (500 minutes) the $20 \%$ blood concentrations in phosphate buffer and sodium acetate had both lysed. With sodium acetate the $20 \%$ blood sample had lysed in a shorter time than the $5 \%$ sample in sodium chloride. Figure 2 shows the clot lysis times under the same experimental conditions as those in Fig. 1 for blood taken from the same subject after exercise. The lysis times for blood diluted with sodium acetate and phosphate were very much shorter than those obtained after rest, but the overall picture was similar. The $20 \%$ blood concentration in acetate lysed in 225 minutes, whilst

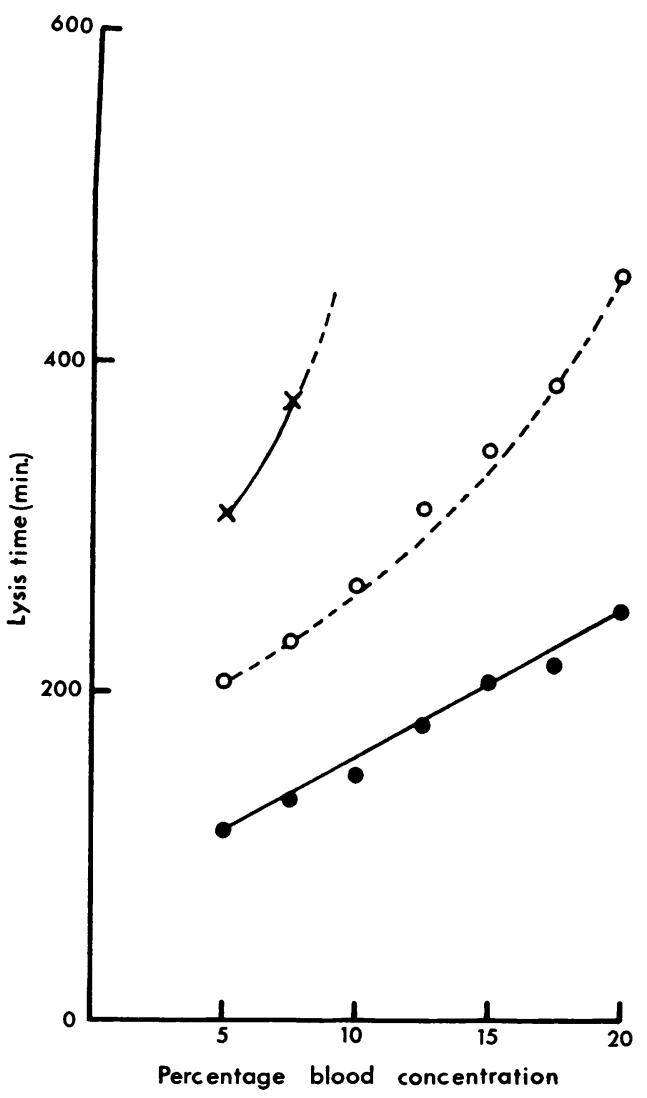

FIG. 1. The relationship between percentage blood concentrations and lysis time of clots prepared from blood taken from a rested subject, and diluted with sodium chloride $\times-\times$, phosphate buffer $\bigcirc-\bigcirc$, and sodium acetate - , all at $0 \cdot 12 \mathrm{M}, \mathrm{pH} 7 \cdot 4$. 


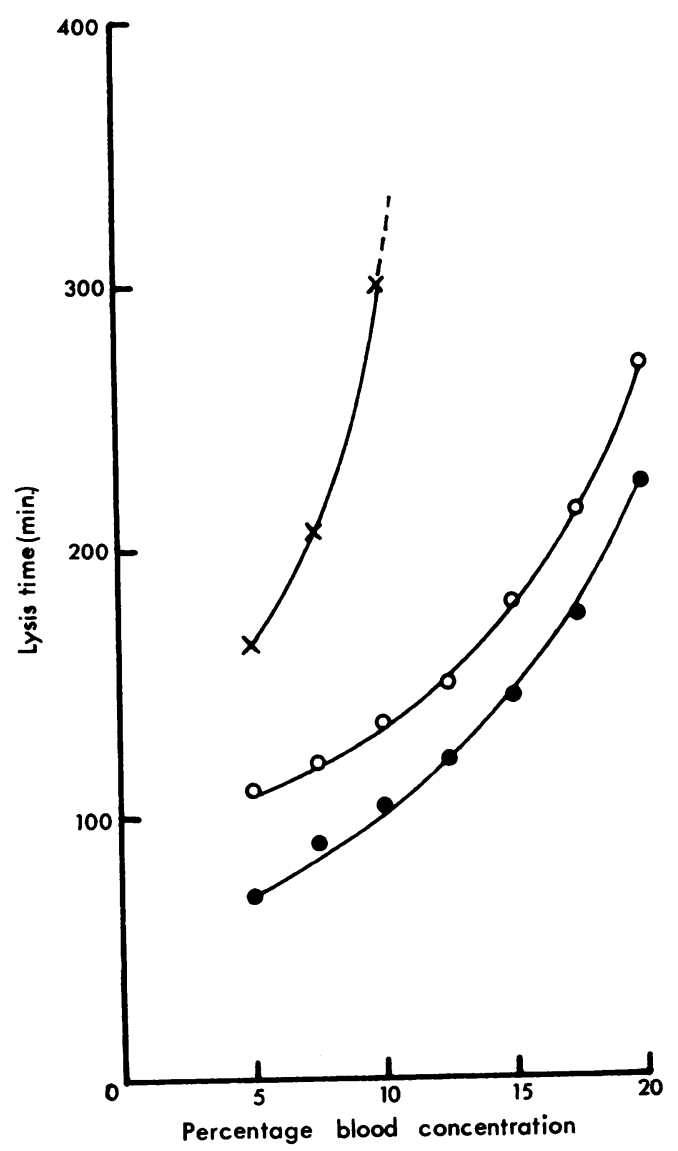

FIG. 2. The relationship between percentage blood concentrations and lysis time of clots prepared from blood taken from the same subject after exercise and diluted with sodium chloride $\times-\times$, phosphate buffer $\bigcirc-\bigcirc$, and sodium acetate $-\mathrm{O}$, all at $0 \cdot 12 \mathrm{M}, \mathrm{pH} 7 \cdot 4$.

the same concentration of blood in phosphate buffer had a lysis time of 270 minutes. When sodium chloride was used as diluent, only the blood concentrations below $12.5 \%$ lysed during the time of observation.

In Fig. 3 is shown the effect of different concentrations of sodium chloride, phosphate and acetate on the plasma inhibition of urokinaseinduced lysis of fibrin clots containing plasminogen. Although the lysis times were much shorter than those obtained in the dilute blood clot system it is noticeable that in the presence of sodium acetate and phosphate the lysis times were only slightly longer than the control without plasma, whilst sodium chloride caused a marked lengthening in the lysis times particularly noticeable at $0 \cdot 15 \mathrm{M}$. An interest- ing feature shown by this experiment is the inability of plasma to cause inhibition in the absence of chloride.

Figure 4 shows the lysis times of clots prepared from the blood of a rested subject diluted with phosphate buffer 2 to give a range of concentrations from 5 to $20 \%$, and of $5 \%$ solutions of the same blood sample in phosphate buffer 2 but with the addition of sufficient sodium chloride to bring the concentrations of chloride to the same levels as $\vec{\circ}$ those present in the blood dilutions in the buffer alone. It is clear from the figure that the lengthening of lysis time with the increase in blood concentration corresponded exactly to the effect of increased

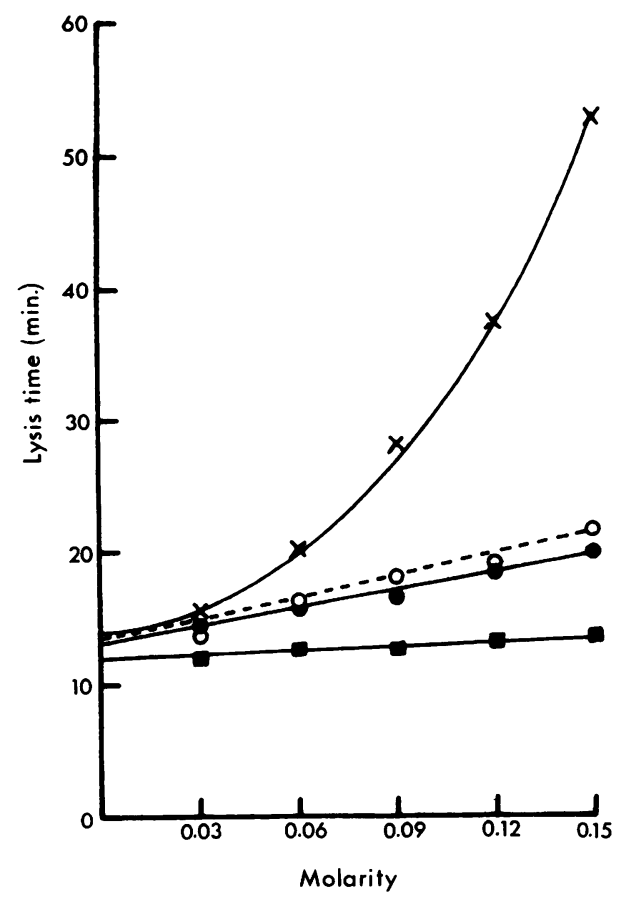

FIG. 3. The effect of different concentrations of sodium acetate $-\mathrm{O}$, sodium phosphate $\bigcirc-\bigcirc$, and sodium $\mathrm{O}$ chloride $\times-\times$ on the lysis times of standard fibrin clots $N$ incorporating $50 \mu l$. of human plasma. —- Controls without plasma.

amounts of sodium chloride in the samples containing a constant amount of blood. This indicates that the variation in lysis time resulting from the dilution of blood is not dependent on the blood $\underset{\mathbb{}}{\stackrel{\circ}{ }}$ concentration, but is the result of diluting the $\frac{\text { Oे }}{\mathbb{Q}}$ chloride ions present in the blood.

Table I shows the lysis times of $10 \%$ blood samples? from three rested male subjects. As in Figs. 1 and $2 \varnothing$ 


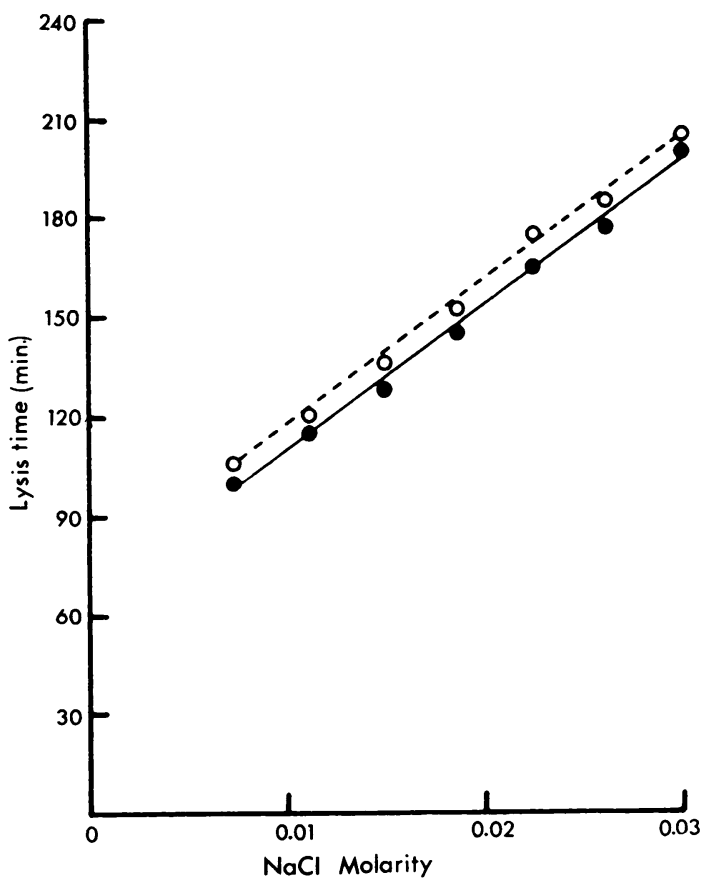

FIG. 4. The comparison between lysis times of different concentrations of blood diluted with phosphate buffer 0 , and $5 \%$ blood concentration with added sodium chloride $\mathrm{O}-\mathrm{O}$.

the diluents were sodium chloride, phosphate buffer 2 , and sodium acetate. It can be seen that dilution of blood with sodium acetate results in a shorter lysis time than when the dilution is performed in phosphate buffer. All of the blood samples diluted with sodium chloride failed to lyse even after incubation for 18 hours.

\section{TABLE I}

LYSIS TIMES OF $10 \%$ BLOOD CLOTS DILUTED WITH SODIUM ACETATE, PHOSPHATE BUFFER, AND SODIUM CHLORIDE ALL AT $p$ H $7 \cdot 4$ 0.12 M. FROM RESTED MALE SUBJECTS

\begin{tabular}{cllc} 
Subject No. & Sodium Acetate & Phosphate Buffer & Sodium Chloride \\
\hline 1 & $2 \mathrm{hr} .45 \mathrm{~min}$. & $3 \mathrm{hr} .35 \mathrm{~min}$. & $>18 \mathrm{hr}$. \\
2 & $3 \mathrm{hr} .25 \mathrm{~min}$. & $7 \mathrm{hr} .05 \mathrm{~min}$. & $>18 \mathrm{hr}$. \\
3 & $4 \mathrm{hr} .20 \mathrm{~min}$. & $7 \mathrm{hr} .35 \mathrm{~min}$. & $>18 \mathrm{hr}$.
\end{tabular}

\section{DISCUSSION}

Fearnley and Lackner (1955) showed that diluted plasma clots lysed most rapidly at a $p \mathrm{H}$ of $7 \cdot 4$ when thrombin was used as the clotting agent. Fearnley, Revill, and Tweed (1952) and Truelove (1953) showed that the use of low-temperature techniques for the separation of plasma was vital for the retention of fibrinolytic activity in plasma. The results described in this communication indicate that lysis of diluted human blood clots depends also upon the ionic strength of the medium in which the dilutions are made and the nature of the ions which it contains.

Macfarlane and Pilling (1946) found no fibrinolytic activity in normal plasma even at a 2,000-fold dilution with buffered saline. Biggs, Macfarlane, and Pilling (1947) also used buffered saline as a diluent and found no fibrinolytic activity in plasma samples from rested subjects although activity could be induced by exercise or adrenaline injection. Fearnley and Lackner (1955) reported that the use of veronal buffer of low ionic strength as diluent gave rise to shorter plasma clot lysis times than buffered saline; however, these were still generally longer than 24 hours.

In 1957 Fearnley, Balmforth, and Fearnley showed that blood from rested female subjects lysed in less than 10 hours when diluted to a concentration of $10 \%$ with phosphate buffer, and their method has been used in numerous investigations on the natural fibrinolytic activity of human blood.

Müllertz (1956) and Dalby and Mertz (1957) observed that when bovine or human plasminogen were activated by streptokinase or urokinase, yields of plasmin were reduced when the reactions were carried out in solutions of high ionic strength. This effect was shown by a variety of ions, and of the salts studied sodium chloride had the most marked effect and sodium acetate the least.

The influence of various ions on the inhibition of urokinase-induced fibrinolysis by human, rabbit, and dog serum in a standard clot system was later investigated (Gallimore, Nulkar, and Shaw, 1965), and it was shown that inhibition was markedly influenced by chloride whilst acetate had little effect; it was also found that when plasma was used instead of serum similar results were obtained. The lysis of dilute blood clots is influenced by ions in the same manner as is the lysis of plasminogen-rich fibrin clots by urokinase in the presence of human plasma. and it is likely that the chloride ions in some way influence an inhibitor of plasminogen activation present in blood and plasma.

The results of these experiments indicate that sodium acetate at $0.12 \mathrm{M}$ and $p \mathrm{H} 7.4$ is to be preferred to phosphate buffer at the same $p \mathrm{H}$ and ionic strength as a diluent for the dilute blood clot assay. Phosphate ions potentiate inhibition more than acetate ions and lead to longer lysis times. The results also indicate that diluted blood and plasma clots lyse, not only because of the dissociation of a plasmin-antiplasmin complex as postulated by 
Macfarlane and Pilling (1946), but also by virtue of the dilution of chloride ions in the blood or plasma.

I wish to thank Dr. R. J. Merrills and Mr. J. T. B. Shaw of this Department for their helpful advice and criticism.

\section{REFERENCES}

Bidwell, E. (1953). Biochem. J., 55, 497.

Biggs, R., Macfarlane, R. G., and Pilling, J. (1947). Lancet, 1, 402. Chakrabarti, R., and Fearnley, G. R. (1962). J. clin. Path., 15, 228.
Dalby, A., and Mertz, E. T. (1957). Amer. J. Physiol., 191, 505.

Fearnley, G. R., Balmforth, G., and Fearnley, E. (1957). Clin. Sci., $16,645$. , and Lackner, H. (1955). Brit. J. Haemat., 1, 189.

-, Revill, R., and Tweed, J. M. (1952). Clin. Sci., 11, 309.

- and Tweed, J. M. (1953). Ibid., 12, 81.

Gallimore, M. J., Nulkar, M. V., and Shaw, J. T. B. (1965). Thrombos. Diathes. haemorrh. (Stuttg.), 14, 145.

Macfarlane, R. G. (1937). Lancet, 1, 10.

-, and Pilling, J. (1946. Ibid., 2, 562.

Mole, R. H. (1948). J. Path. Bact., 60, 413.

Müllertz, S. (1956). Acta physiol. scand., 38, suppl. 130.

Truelove, S. C. (1953). Clin. Sci., 12, 75. 